\title{
latrogenic ischiofemoral impingement due to high tibial osteotomy with overvalgization: a case report
}

\author{
Christian Konrads $^{1 *}$, Sufian S. Ahmad ${ }^{1,2}$, Tina Histing ${ }^{1}$ and Maher Ibrahim ${ }^{3}$
}

\begin{abstract}
Background: Open wedge high tibial osteotomy is a standard procedure for frontal realignment. It is indicated in varus knee with reduced mechanical medial proximal tibia angle. Overcorrection producing a mechanical medial proximal tibia angle out of the normal range $\left(85-90^{\circ}\right)$ is not recommended because this would lead to unphysiological joint-line orientation. Osteotomies around the knee also influence the adjacent ankle and hip joints. For the hip, it is known that frontal alignment of the leg influences the ischiofemoral space. A decreased ischiofemoral space can lead to painful impingement between the ischial bone and the lesser trochanter.

Case presentation: A 53-year-old German woman presented with severe ischiofemoral impingement symptoms and valgus malalignment of the left leg after open wedge high tibial osteotomy, which was indicated and performed by an orthopedic surgeon with intention to treat medial knee pain due to degenerative arthritis of the medial compartment years after medial meniscectomy. The mechanical medial proximal tibia angle was $100.5^{\circ}$. We performed closed wedge high tibial osteotomy producing a mechanical medial proximal tibia angle of $90.0^{\circ}$ and normal jointline orientation. The hip pain was gone immediately after the surgery, and the patient had no signs of ischiofemoral impingement or hip pain at last follow-up 12 months after closed wedge high tibial osteotomy.

Conclusions: Frontal realignment osteotomy around the knee can create problems at adjacent joints. Overvalgization of the proximal tibia made the patient compensate by hyperadduction of the hip to enable full foot sole contact with the floor. Hyperadduction of the hip decreased the ischiofemoral space, leading to severe impingement. Therefore, meticulous planning of osteotomies is important not to produce unphysiological situations or unwanted negative effects at the level of an adjacent joint.
\end{abstract}

Keywords: Hip, Knee, Malalignment, Realignment, Varus, Valgus

\section{Background}

Open wedge high tibial osteotomy (owHTO) is a standard procedure for frontal realignment $[1,2]$. It is indicated in varus knee with reduced mechanical medial proximal tibia angle (mMPTA) [3]. Overcorrection producing a mMPTA out of the normal range $\left(85-90^{\circ}\right)$ is not

*Correspondence: christian.konrads@gmail.com

1 Department for Trauma and Reconstructive Surgery, BG Klinik, University of Tübingen, Schnarrenbergstr. 95, 72076 Tübingen, Germany

Full list of author information is available at the end of the article recommended because this would lead to unphysiological joint-line orientation $[4,5]$.

Osteotomies around the knee also influence the adjacent joints-ankle and hip [6-9]. For the hip, it was demonstrated earlier that frontal alignment of the leg influences the ischiofemoral space [9], but this has not become common knowledge yet. A decreased ischiofemoral space can lead to impingement between the ischial bone and the lesser trochanter [7, 9]. This is demonstrated and illustrated by the present case. original author(s) and the source, provide a link to the Creative Commons licence, and indicate if changes were made. The images or other third party material in this article are included in the article's Creative Commons licence, unless indicated otherwise in a credit line to the material. If material is not included in the article's Creative Commons licence and your intended use is not permitted by statutory regulation or exceeds the permitted use, you will need to obtain permission directly from the copyright holder. To view a copy of this licence, visit http://creativecommons.org/licenses/by/4.0/. The Creative Commons Public Domain Dedication waiver (http://creativeco mmons.org/publicdomain/zero/1.0/) applies to the data made available in this article, unless otherwise stated in a credit line to the data. 
Unphysiological valgus knee alignment is normally compensated by the patient by adducting the hip to enable full foot sole contact with the floor [9]. As hip adduction decreases the space between the ischial bone of the pelvis and the lesser trochanter of the femur, ischiofemoral impingement can result [9]. This is known to be an important extraarticular source of hip pain.

\section{Case presentation}

A 53-year-old German woman presented with severe ischiofemoral impingement symptoms and valgus malalignment of the left leg after owHTO, which was indicated and performed by an orthopedic surgeon with intention to treat medial knee pain due to degenerative arthritis of the medial compartment years after medial

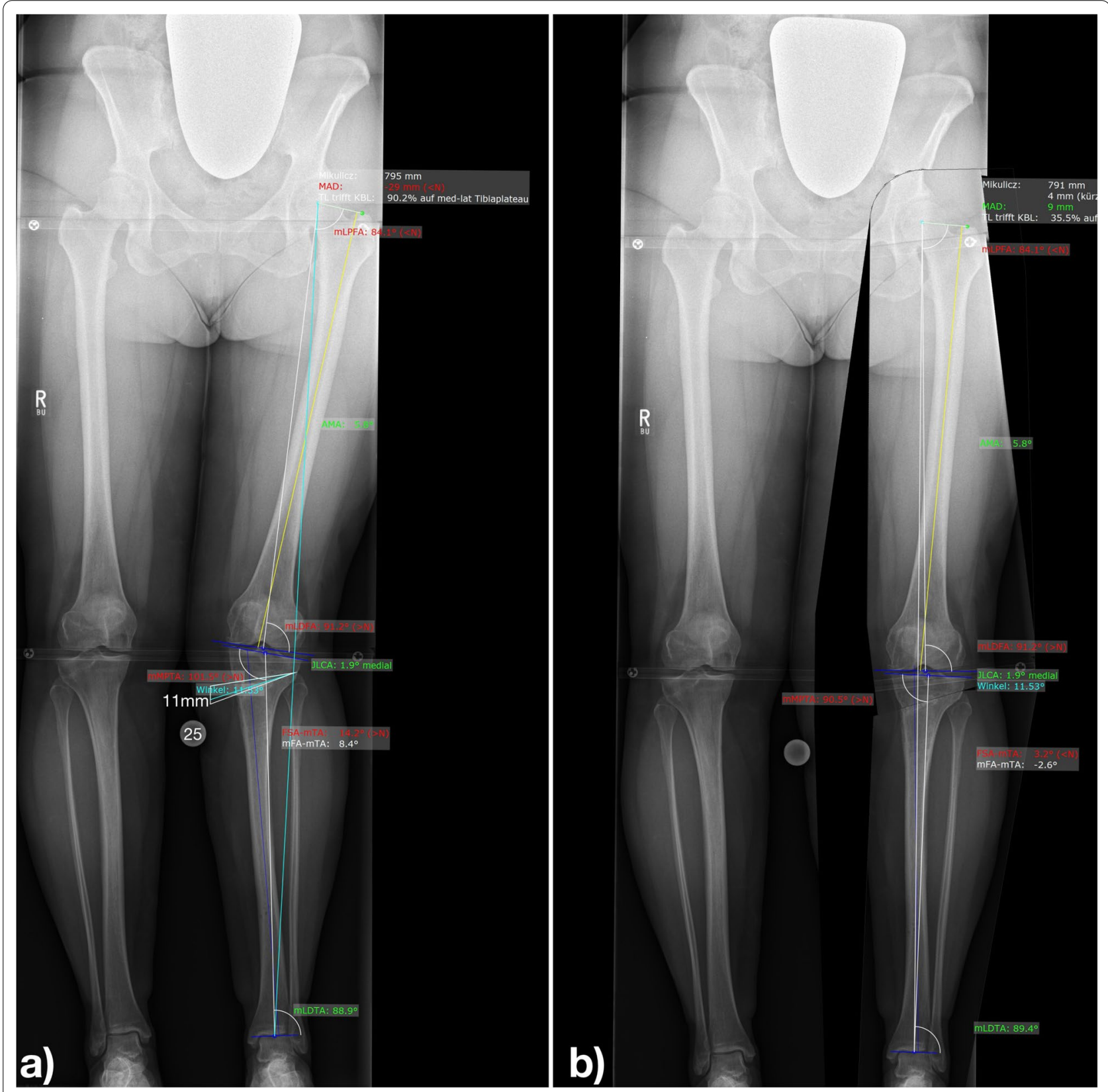

Fig. 1 Long-leg standing radiograph. a Valgus aligned knee with oblique joint-line and minimal ischiofemoral space between the ischial bone and the lesser trochanter. Using mediCAD software, a medial closed wedge high tibial osteotomy for varization is planned on the native X-ray showing the planned surgical procedure (11-mm closed wedge high tibial osteotomy) and $\mathbf{b}$ the planned result after osteotomy 


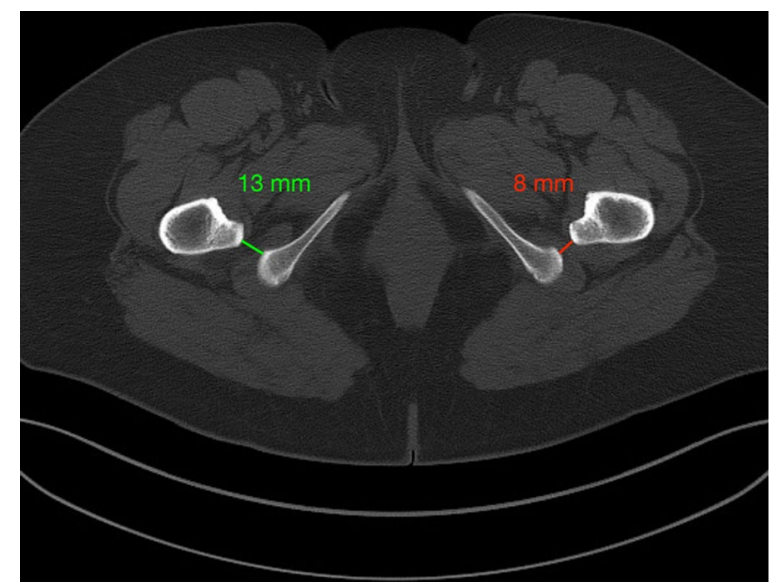

Fig. 2 Axial computed tomography slide at level of lesser trochanters. The ischiofemoral distance is smaller on the left than right side

meniscectomy. The initial osteotomy was performed 4 years previously, and the patient has been severely symptomatic since this surgery.

On clinical examination, the Faber test was positive and external rotation of the hip in extension was painful, too. Radiologically, the mMPTA was $101.5^{\circ}$ (Fig. 1a). The patient almost could not walk because she needed to adduct her left hip so much to enable her foot to approach the floor evenly. With a positive Faber test, psoas sign, and posterior impingement test, the range of motion (ROM) of the affected hip was Ext/Flex 0/0/120, Abd/Add $45 / 0 / 0^{\circ}$, Aro/Iro 40/0/15 . The WOMAC score was 20.3. The Merle D'Aubigné and Postel score was 13. Torsional malalignment was excluded by torsional CT analysis. On axial CT slides, a reduced ischiofemoral distance was found on the affected left side (Fig. 2).

We planned (Fig. 1a, b) and performed cwHTO producing a mMPTA of $90.0^{\circ}$ and normal joint-line orientation (Fig. 3). The hip pain was gone immediately after surgery, and the patient had no signs of ischiofemoral impingement or hip pain at the last follow-up 12 months after cwHTO. At this time, the ROM was Ext/ Flex $10 / 0 / 120^{\circ}$, Abd/Add $45 / 0 / 25^{\circ}$, Aro/Iro $45 / 0 / 20^{\circ}$. The WOMAC score was 87.5 , and the Merle D'Aubigné and Postel score was 18.

\section{Discussion and conclusions}

In the presented case of a 53-year-old patient, massive overvalgization of about $10^{\circ}$ deteriorated the function of the lower extremity tremendously. In varus situations of the knee due to medial joint space narrowing without bony malalignment per se, one should be cautious when performing realignment osteotomies. In these cases,

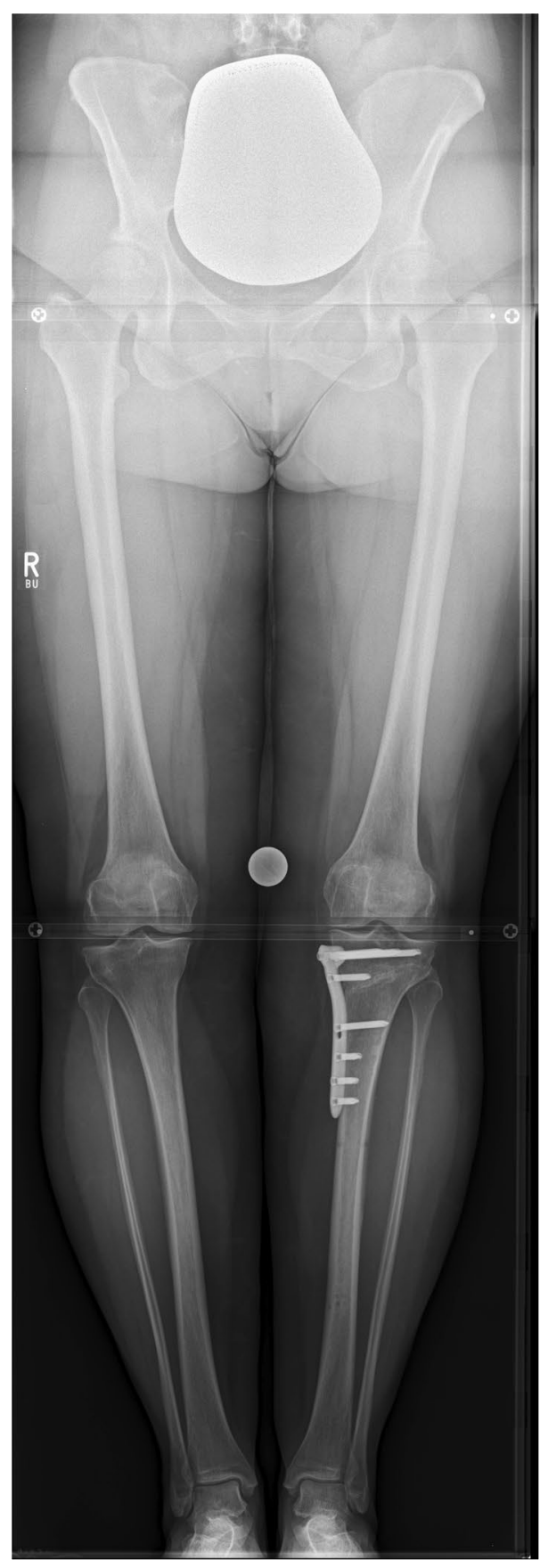

Fig. 3 Long-leg standing radiograph showing normal knee alignment and increased ischiofemoral space postoperatively (after closed wedge high tibial osteotomy)

medial unicompartmental knee arthroplasty might be more appropriate.

For sufficient preoperative planning, it is recommended to at least analyze the long-leg axis, the joint-line convergence angle (JLCA), and the following bony angles around the knee on a standardized long-leg standing radiograph: 
mechanical lateral distal femur angle (mLDFA) and mMPTA [10-12]. Figure 1 shows the computer-aided digital planning, which was conducted preoperatively.

Slight overvalgization is accepted in cases with medial gonarthritis, but no unphysiological bony angles or oblique JLCA should be created. To avoid this, often double-level osteotomy of the proximal tibia and the distal femur is indicated in cases with bony malalignment [4, $13,14]$. It was demonstrated earlier that joint-line obliquity (JLO) of more than $3^{\circ}$ is associated with worse clinical outcomes after medial owHTO [15]. Overcorrection of more than $3^{\circ}$ should be avoided [15].

In conclusion, frontal realignment osteotomy around the knee can create problems at the hip. Overvalgization of the proximal tibia made the patient compensate by hyperadduction of the hip to enable full foot sole contact with the floor. Hyperadduction of the hip decreased the ischiofemoral space, leading to severely painful symptoms of ischiofemoral impingement. Therefore, meticulous planning of osteotomies according to the described principles is important to avoid unphysiological situations or unwanted negative effects at the knee or the level of an adjacent joint.

\section{Abbreviations}

CT: Computed tomography; cw: Closed wedge; HTO: High tibial osteotomy; JLCA: Joint-line convergence angle; JLO: Joint-line obliquity; mLDFA: Mechanical lateral distal femur angle; mMPTA: Mechanical medial proximal tibia angle; ow: Open wedge; ROM: Range of motion;WOMAC: Western Ontario and McMaster Universities Osteoarthritis.

\section{Acknowledgements}

We acknowledge support by Open Access Publishing Fund of University of Tübingen.

\section{Authors' contributions}

CK planned this work, analyzed the data, and wrote the manuscript. SSA planned this work, collected and analyzed the data, and revised the manuscript. TH supervised this work. MI wrote and revised the manuscript. All authors read and approved the final manuscript.

\section{Funding}

No funding was received for this work.

\section{Availability of data and materials}

The datasets used and analyzed are available from the corresponding author on reasonable request.

\section{Declarations}

Ethics approval and consent to participate

Informed consent was obtained. This work does not consist of studies in humans or animals.

\section{Consent for publication}

Written informed consent was obtained from the patient for publication of this case report and any accompanying images. A copy of the written consent is available for review by the Editor-in-Chief of this journal.

\section{Competing interests}

The authors declare that they have no competing interests.

\section{Author details}

'Department for Trauma and Reconstructive Surgery, BG Klinik, University of Tübingen, Schnarrenbergstr. 95, 72076 Tübingen, Germany. ${ }^{2}$ Center for Musculoskeletal Surgery, Charité - University Medical Center Berlin, Berlin, Germany. ${ }^{3}$ Department of Orthopaedic Surgery, Nyon Hospital, Nyon, Switzerland.

Received: 20 July 2021 Accepted: 4 January 2022

Published online: 04 February 2022

\section{References}

1. Staubli AE, De Simoni C, Babst R, Lobenhoffer P. TomoFix: a new LCPconcept for open wedge osteotomy of the medial proximal tibia. Injury. 2003;34(Suppl 2):B55-62.

2. Agneskirchner JD, Hurschler C, Wrann CD, Lobenhoffer P. The effects of valgus medial opening wedge high tibial osteotomy on articular cartilage pressure of the knee: a biomechanical study. Arthroscopy. 2007:23(8):852-61.

3. Schröter S, Mueller J, van Heerwaarden R, Lobenhoffer P, Stöckle U, Albrecht D. Return to work and clinical outcome after open wedge HTO. Knee Surg Sports Traumatol Arthrosc. 2013;21(1):213-9.

4. Feucht MJ, Winkler PW, Mehl J, Bode G, Forkel P, Imhoff AB, Lutz PM. Isolated high tibial osteotomy is appropriate in less than two-thirds of varus knees if excessive overcorrection of the medial proximal tibial angle should be avoided. Knee Surg Sports Traumatol Arthrosc. 2020. https://doi.org/10. 1007/s00167-020-06166-3.

5. Iseki T, Onishi S, Kanto M, Kanto R, Kambara S, Yoshiya S, Tachibana T, Nakayama H. Double-level osteotomy for severe varus osteoarthritic knees can prevent change in leg length and restore physiological joint geometry. Knee. 2021;31:136-43.

6. Konrads C, Ahrend MD, Beyer MR, Stöckle U, Ahmad SS. Supracondylar rotation osteotomy of the femur influences the coronal alignment of the ankle. J Exp Orthop. 2021;8(1):32.

7. Konrads C, Ahrend MD, Beyer MR, Stöckle U, Ahmad SS. Rotation osteotomy of the distal femur influences coronal femoral alignment and the ischiofemoral space. Arch Orthop Trauma Surg. 2021. https://doi.org/10.1007/ s00402-020-03704-z.

8. Konrads C, Eis A, Ahmad SS, Stöckle U, Döbele S. Osteotomies around the knee lead to corresponding frontal realignment of the ankle. Eur J Orthop Surg Traumatol. 2021. https://doi.org/10.1007/s00590-021-03016-x.

9. Ahmad SS, Konrads C, Stöckle U, Ahrend MD. The ischiofemoral space of the hip is influenced by the frontal knee alignment. Knee Surg Sports Traumatol Arthrosc. 2021;29(8):2446-52.

10. Schröter S, Elson DW, Ateschrang A, Ihle C, Stöckle U, Dickschas J, Harrer J. Lower limb deformity analysis and the planning of an osteotomy. J Knee Surg. 2017;30(5):393-408.

11. Na YG, Lee BK, Choi JU, Lee BH, Sim JA. Change of joint-line convergence angle should be considered for accurate alignment correction in high tibial osteotomy. Knee Surg Relat Res. 2021;33(1):4.

12. Park JG, Bin SI, Kim JM, Lee BS. Using the lower limb adduction angle to predict postoperative knee joint-line obliquity after open-wedge high tibial osteotomy. Ortho J Sports Med. 2021;9(5):23259671211003990.

13. Sohn S, Koh IJ, Kim MS, In Y. Risk factors and preventive strategy for excessive coronal inclination of tibial plateau following medial opening-wedge high tibial osteotomy. Arch Orthop Traum Surg. 2021. https://doi.org/10.1007/ s00402-020-03660-8.

14. Akamatsu Y, Nejima S, Tsuji M, Kobayashi H, Muramatsu S. Joint line obliquity was maintained after double-level osteotomy, but was increased after open-wedge high tibial osteotomy. Knee Surg Sports Traumatol Arthrosc. 2021. https://doi.org/10.1007/s00167-020-06430-6.

15. Song JH, Bin SI, Kim JM, Lee BS. What is an acceptable limit of joint-line obliquity after medial open wedge gith tibial osteotomy? Analysis based on midterm results. Am J Sports Med. 2020;48(12):3028-35.

\section{Publisher's Note}

Springer Nature remains neutral with regard to jurisdictional claims in published maps and institutional affiliations. 